\title{
A COMUNICAÇÃO CIENTÍFICA E A URGÊNCIA NA DEMOCRATIZAÇÃO DO CONHECIMENTO
}

A comunicação científica fundamenta-se na informação científica, responsável pelo conhecimento científico. Portanto, essa comunicação está envolvida tanto nas atividades de produção quanto de disseminação e uso da informação. A pesquisa científica está no alicerce da comunicação científica.

No cotidiano da academia, percebe-se que há um círculo quase que natural em que os pesquisadores são, invariavelmente, consumidores de informação (para executar suas próprias pesquisas); produtores de informação (para divulgar suas próprias pesquisas); e avaliadores de informação (para validar, ou não, os achados dos demais membros da comunidade científica) ${ }^{1}$.

Entretanto, urge que este círculo seja alargado de modo que o fluxo informacional do conhecimento científico extrapole os limites da comunidade científica e chegue às coletividades. A etapa da divulgação científica deve alcançar a população para a democratização de oportunidades, transformando-a em alfabetizada cientificamente, uma vez que Ciência, Tecnologia e Inovação (CT\&I) determinam a evolução da humanidade, o que requer dos cidadãos habilidades para desvendarem 0 universo da Ciência, tendo em vista que a inacessibilidade aos novos conhecimentos cerceia a prática cidadã ${ }^{1}$.

Portanto, cientes do caráter social da CT\&I, é imprescindivel divulgar resultados das pesquisas e estimular a translação do conhecimento de modo a aplicar os resultados na prática. A pesquisa científica e a divulgação dos seus resultados são atividades indissociáveis, no sentido de que qualquer investigação de natureza científica só se consolida quando os dados obtidos são devidamente divulgados, não apenas para a comunidade científica.

A função social do pesquisador e o seu compromisso com a popularização/democratização da Ciência requer divulgação dos resultados da sua pesquisa para além dos canais formais de divulgação da Ciência (periódicos, eventos, livros, e-books), visando combater o "analfabetismo científico" (impossibilidade de acesso ou dificuldade de assimilar as informações e os conhecimentos disponíveis) ${ }^{2}$.

Uma das estratégias de popularização da CT\&I que vem sendo implementada no Brasil como uma Política de Estado é a Semana Nacional de Ciência e Tecnologia (SNCT), que este ano realizou a sua $18^{a}$ edição, com o tema: "A transversalidade da ciência, tecnologia e inovações para o planeta".

A SNCT é realizada anualmente, no mês de outubro, com atividades coordenadas pelo Ministério da Ciência, Tecnologia e Inovação (MCTI), e objetiva debater, estimular e realizar atividades de popularização da CT\&I e desenvolver a cultura científica nas escolas, universidades, comunidades, museus, instituições científico-culturais e locais públicos ${ }^{3}$.

Os debates sobre temas e ações transversais não são novidade no meio da Ciência, da Tecnologia e das Inovações nem se restringem a um ou outro campo do conhecimento. A transversalidade é alcançada quando ocorre a máxima interação e comunicação entre diversas estruturas, não apenas disciplinares, mas também as que se refletem no dia a dia da sociedade. "Transversal" é o que cruza espaços delimitados, o que atravessa e articula as estruturas sociais e do conhecimento humano. É o que é comum a todos ${ }^{3}$.

Quando nos reportamos à importância do conhecimento científico e tecnológico tanto no meio acadêmico quanto para a sociedade, entendemos a necessidade de discutir e refletir medidas que são essenciais para o avanço do conhecimento, tais como: a promoção de debates sobre o papel da pesquisa científica para a sociedade, a promoção de encontros da academia com a iniciativa privada, o apoio à iniciativa do acesso aberto a publiçções científicas.

Com o intuito de conhecer a visão, o interesse e o grau de informação da população em relação à CT\&I no país, o Ministério da Ciência, Tecnologia, Inovações e Comunicações (MCTIC) e o Centro de Gestão e Estudos Estratégicos (CGEE) realizaram, no ano de 2019, a quinta rodada da pesquisa "Percepção pública da ciência e tecnologia no Brasil". Foram entrevistadas 2.200 pessoas com idades 
entre 16 e 75 anos, de todas as regiões do país. Em comparação com edições anteriores, reafirmou o interesse dos brasileiros por temas de natureza da ciência e a elevada confiança na ciência e nos cientistas, mas também um escasso acesso à informação científica, uma baixa apropriação do conhecimento e uma desigualdade tanto na informação quanto na participação em atividades de difusão cultural, entre outros aspectos ${ }^{4}$.

Outra pesquisa realizada, dessa vez pelo Instituto Nacional de Ciência e Tecnologia em Comunicação Pública da Ciência e Tecnologia (INCT-CPCT), com financiamento do Conselho Nacional de Desenvolvimento Científico e Tecnológico (CNPq), ouviu também, em 2019, por meio de questionários estruturados, 2.206 jovens entre 15 e 24 anos, em situação urbana, residentes em 79 cidades de todas as regiões do Brasil ${ }^{5}$.

De acordo com o levantamento, apesar de majoritariamente demonstrarem confiança nos cientistas e interesse por temas científicos, a maioria dos jovens participantes do estudo, incluindo os de curso superior, não consegue citar o nome de uma instituição nacional de pesquisa nem de algum cientista brasileiro. Só $5 \%$ deles souberam dizer o nome de algum cientista brasileiro. Uma questão que chama a atenção é que muitos jovens estão ou poderiam estar na universidade e, ainda assim, não identificam as universidades brasileiras como local em que se faz pesquisa - embora $95 \%$ da produção científica brasileira seja feita em universidades. Além disso, $40 \%$ concordaram com a afirmação de que, "se a ciência não existisse, meu dia a dia não mudaria muito" - apesar de a Ciência estar por trás de todos os produtos que utilizamos no nosso dia a dia, das roupas e alimentos aos remédios e aparelhos eletrônicos ${ }^{5}$.

0 resultado joga luzes sobre a urgência da democratização/popularização do conhecimento diante do desconhecimento muito grande dos jovens sobre conceitos básicos de Ciência e sobre como a Ciência e a Tecnologia são produzidas no Brasil.

As pesquisas supracitadas apresentam pistas para que nós, professores e pesquisadores, sejamos mais ativos, criativos e inventivos em divulgar a Ciência que produzimos. Precisamos, dentre outras iniciativas, articular a pesquisa e a extensão universitária, defender uma política de Ciência Aberta e incorporar estratégias da Ciência Cidadã, apropriar-nos de ferramentas de divulgação científica para distintos e variados públicos. Fica o convite aos pesquisadores para a promoção de um diálogo mais efetivo com a sociedade.

Profa. Dra. Maristela Inês Osawa Vasconcelos

Enfermeira. Docente da Universidade Estadual Vale do Acaraú - UVA

\section{REFERÊNCIAS}

1. Targino MG, Torres NH. Comunicação Científica Além da Ciência. Ação Midiática - Estudos em omunicação, Sociedade e Cultura [serial on the internet]. 2014 [cited 2021 Nov 25]; 1(7). Available from: https://revistas. ufpr.br/acaomidiatica/article/view/36899/22924

2. Targino MG. Divulgação de resultados como expressão da função social do pesquisador. Intercom: Revista Brasileira de Ciências da Comunicação. 2001. 24(1):11-35.

3. Brasil. Semana Nacional de Ciência e Tecnologia [homepage on the internet]. Brasília (DF): Ministério da Ciência, Tecnologia e Inovações; 2019 [cited 2021 Nov 25]. Available from: https://semanact.mcti.gov.br/ entenda-como-funciona-a-semana-snct/

4. Brasil. Percepção pública da C\&T no Brasil - 2019. Resumo executivo. Brasília (DF): Centro de Gestão e Estudos Estratégicos; 2019. Available from: https://www.cgee.org.br/web/percepcao

5. Massarani L, Castelfranchi Y, Fagundes V, Moreira I, coordenadores. 0 que os jovens brasileiros pensam da ciência e da tecnologia? Rio de Janeiro: Fiocruz/COC; INCT-CPCT; 2021. 